\title{
Unusual ventricular activation produced by temporary transvenous cardiac pacing: electrovectorcardiographic findings
}

\author{
Activación ventricular inusual producida por estimulación cardíaca transvenosa \\ temporal: hallazgos electrovectorcardiográficos
}

\author{
Andrés R. Pérez-Riera ${ }^{*}$, Raimundo Barbosa-Barros ${ }^{2}$, Fábio Baueb-Soler ${ }^{3}$, \\ Rodrigo Daminello-Raimundo', Luiz C. de Abreu' y Kjell Nikus ${ }^{4}$
}

${ }^{1}$ Laboratorio de Metodología de la Investigación y Escritura Científica, Faculdade de Medicina do ABC, Santo André; ${ }^{2}$ Centro Coronario, Hospital de Messejana Dr. Carlos Alberto Studart Gomes, Fortaleza; ${ }^{3}$ Departamento de Cardiología, Clínica Médica e Diagnóstica Soler, São Paulo, Brazil; ${ }^{4}$ Centro del Corazón, Tampere University Hospital and Faculty of Medicine and Health Technology, Tampere, Finland

\begin{abstract}
Complete heart block (CHB) results from dysfunction of the cardiac conduction system, which results in complete electrical dissociation. The ventricular escape rhythm can have its origin anywhere from the atrioventricular node to the bundle branch-Purkinje system. CHB typically results in bradycardia, hypotension, fatigue, hemodynamic instability, syncope, or even Stokes-Adams syndrome. Escape rhythm originating above the bifurcation of the His bundle (HB) produces narrow QRSs with relatively rapid heart rate (HR) (except in cases of His system disease). We present a middle-aged man with an HR of $34 \mathrm{bpm}$, progressive fatigue, in whom a temporary pacemaker was implanted in the subtricuspid region. The post-intervention electrocardiogram had unusual features.
\end{abstract}

Key words: Temporary transvenous cardiac pacing. Complete atrioventricular block. Left septal fascicular block.

\section{Resumen}

El bloqueo cardíaco completo (BCC) resulta de la disfunción del sistema de conducción cardíaco, lo que ocasiona una disociación eléctrica completa entre aurículas y ventrículos. El ritmo de escape resultante puede tener su origen en cualquier lugar desde el nodo auriculoventricular hasta el sistema His Purkinje. EI BCC generalmente produce bradicardia, hipotensión, fatiga, inestabilidad hemodinámica, síncope o incluso el síndrome de Stokes-Adams. El ritmo de escape que se origina por encima de la bifurcación del haz de His produce intervalos QRS estrechos con frecuencia cardíaca no muy lenta (excepto en casos de enfermedad del sistema Hisiano). Presentamos a un hombre de mediana edad con una frecuencia cardíaca de $34 \mathrm{lpm}$, fatiga progresiva, en el que se implantó un marcapasos temporario en la región subtricuspídea. El electrocardiograma resultante a la intervención presentó características inusuales.

Palabras clave: Marcapaso temporario tranvenoso. Bloqueo cardiaco completo. Bloqueo de las fibras medio de rama izquierda.

\section{Correspondencia:}

*Andrés Ricardo Pérez-Riera

E-mail: riera@uol.com.br
Fecha de recepción: 25-03-2019

Fecha de aceptación: 11-07-2019

DOI: 10.24875/ACM.19000167
Disponible en internet: 13-09-2019

Arch Cardiol Mex. 2020;90(1):16-20 www.archivoscardiologia.com BY-NC-ND (http://creativecommons.org/licenses/by-nc-nd/4.0/). 


\section{Introduction}

The left septal fascicular block (LSFB) was contested until recently, but in recent years has been confirmed by employing several methods, such as electro-vectorcardiogram, exercise stress testing, electrophysiological atrial extra stimuli and anatomical studies of ungulate and human hearts using contrast-enhanced micro-computed tomography associated with high-resolution three-dimensional imaging of the human cardiac conduction system. The main cause of LSFB is coronary artery disease with proximal obstruction of the left anterior descending coronary artery before its first perforator branch. The demonstration of its transient form is a compelling fact to rule out other causes responsible for prominent anterior QRS forces. In the present case, we describe for the first time in the literature to our knowledge, ventricular activation with the association of left anterior fascicular block (LAFB) + left septal fascicular block (LSFB) during temporary transvenous pacemaker implanted in the subtricuspid region.

\section{Case report}

Male 47 years old, Caucasian from Fortaleza city, Brazil, who complained of progressive fatigue for 3 months with worsening in the last month. No syncope, dizziness or palpitations.

Family history: nothing worthy of note. Physical: heart rate $35 \mathrm{bpm}$ without murmurs, blood pressure: $110 / 70 \mathrm{mmHg}$. Normal laboratory tests. The electrocardiogram (ECG) is shown in Fig. 1. A temporary transvenous pacemaker was implanted through the left subclavian vein. The lead was placed in the subtricuspid area. ECG/vectorcardiography (VCG) performed immediately after this procedure showed an unusual pattern (Fig. 2).

Fig. 3 shows the ventricular activation pathway in the horizontal and right sagittal views.

\section{Discussion}

El-Sherif et al., ${ }^{1}$ in an experimental model, and Narula et al., ${ }^{2}$ in humans, showed that a lesion in the His bundle $(\mathrm{HB})$ produced classical changes of bundle branch block (BBB). These researchers explained the finding on the basis of longitudinal dissociations. It meant that certain fibers within the HB are predestined to function in the same manner as fibers in the BBBs or fascicles. Pacing proximal to the lesion produced QRS morphology and axis identical with the baseline sinus rhythm, whereas pacing a few millimeters distally resulted in BBB. An explanation for these findings is anisotropic conduction. For example, anisotropic reentry results in greater conduction velocity in longitudinal direction of the fibers and slower conduction with transversal fiber orientation. This velocity difference favoring the longitudinal direction is a consequence of the greater density of the so-called "gap junctions" in the ends of the cells in comparison to the lateral area, which will provide sufficient delay to produce a BBB because the His-Purkinje system (HPS) impulse feed distal to the lesion may be delayed sufficiently and can be overcome by pacing distally.

Ever since Rosenbaum et al. described their findings, there has been an assumption that the left bundle branch (LBB) has only two fascicles. Many investigators before and subsequently have presented strong evidence to suggest that there are three divisions of the LBB, and therefore, the terms fascicular blocks have been preferred over the term hemiblocks. Trifascicular LBB should not be confused with trifascicular atrioventricular (AV) block. The latter term evolved when there was a combination of two fascicles showing block and additional first-degree AV block. This was thought to reflect the conduction delay in the third fascicle. This line of thinking did not pan out because in many cases, the PR prolongation was due to AV nodal delay and not additional HPS conduction block. Some aspects of the fascicles of the LBB need further discussion, especially with regard to the existence and physiologic/pathophysiologic role of the left septal fascicle (LSF).

A component of vertical orientation has been used in the definition of fascicular blocks because this diagnosis was made by the QRS orientation in the frontal plane. Hence, the left anterior fascicle (LAF) becomes anterosuperior, and the left posterior fascicle (LPF) has been termed posteroinferior.

The presence of an LSF as a separate division has been implied by several investigators; although pathologic specimens clearly show the LSF in humans ${ }^{3}$, the clinical aspects of the left septal fascicular block (LSFB) have not been convincingly demonstrated until recently using ECG/VCG ${ }^{4}$. Demoulin and Kulbertus reinforced earlier studies of the trifascicular nature of the left conduction system, demonstrating a third branch in 11 of 20 hearts $^{5,6}$. Kulbertus et al. showed that the majority of examined hearts had an LSF that was easily identifiable ${ }^{7,8}$.

Ungulate hearts demonstrated the trifascicular nature of the LBB $^{9}$. In addition, Stephenson et al. 


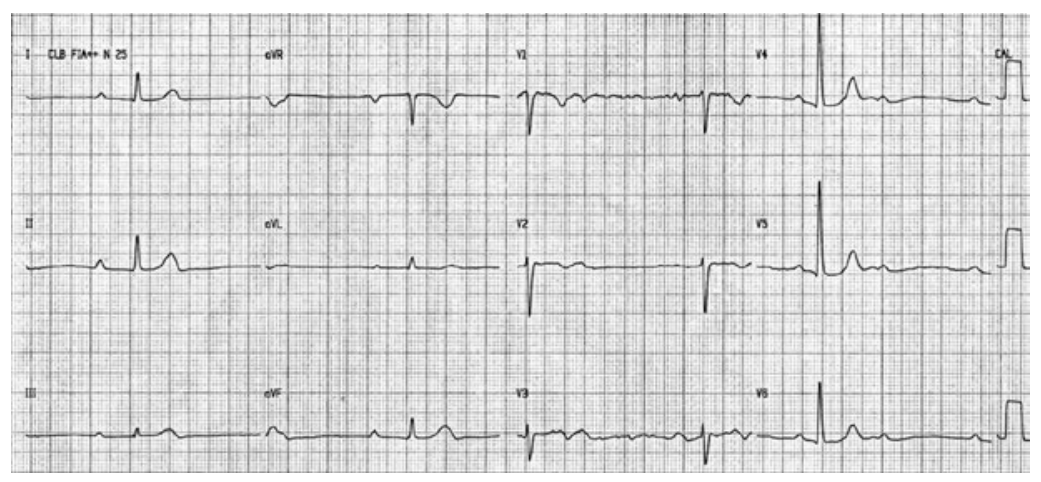

Figure 1. Electrocardiogram (ECG) at admission. 12-lead ECG-1: complete heart block, heart rate 34 bpm, narrow $0 R S$ complex with QRS axis at $+40^{\circ}$.

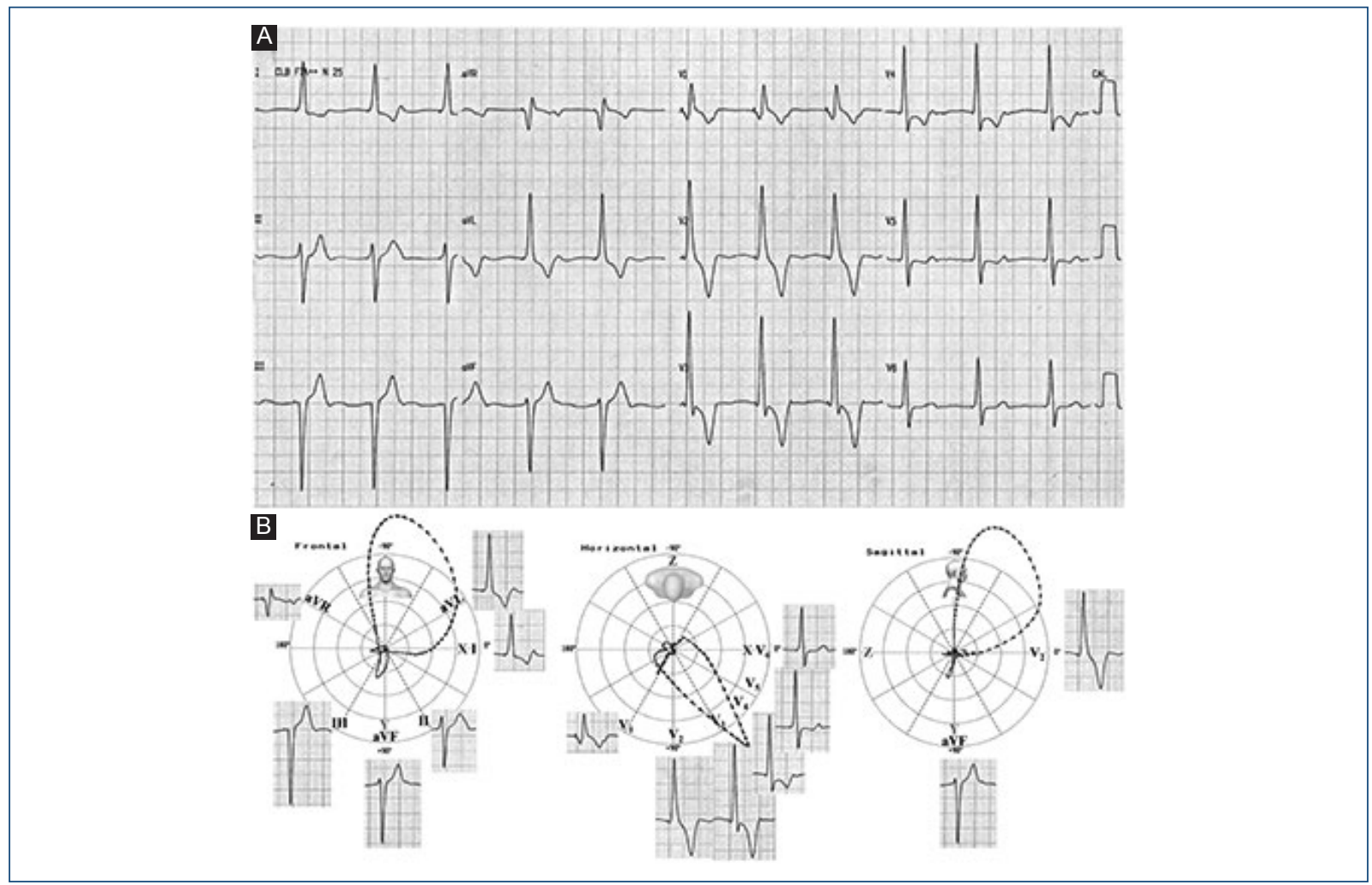

Figure 2. 12-lead electrocardiogram (ECG)/vectorcardiography (VCG) performed after temporary transvenous pacemaker implantation. A: ECG: pacemaker rhythm, QRS duration $160 \mathrm{~ms}$, extreme left axis deviation ( $\mathrm{QRS}$ axis at $-55^{\circ}$ ), rS pattern in the inferior leads, SIII > SII, wide R-wave without initial q wave in I and aVL. This indicates atypical left anterior fascicular block (LAFB) by the absence of the first middle septal vector. In the precordial leads, prominent anterior QRS forces: $q R$ pattern in the right precordial leads, R-wave voltage "in crescendo" from $\mathrm{V}_{1}$ to $\mathrm{V}_{3}$, and Rs-type QRS with decreasing $R$-wave amplitude from $V_{4}$ to $V_{6}$. The absence of initial $q$ wave in $V_{5}$ to $V_{6}$ indicating lack of first mid-septal vector. These ECG findings are compatible with the left septal fascicular block (LSFB). B: VCG: frontal plane: initial 20 ms vector with slow inscription and directed from right to left, extreme left axis deviation (SÂQRS $-50^{\circ}$ ). ORS loop predominantly located in the upper left quadrant and final vectors with slow inscription in the right superior quadrant. T-loop with clockwise rotation in the inferior right quadrant $\left(\approx+110^{\circ}\right)$. Horizontal plane: visible spike of pacing (a), initial 20 ms vector of slow inscription and directed to the back and leftward signaling initial activation dependent on the LPF. ORS loop predominantly located in the left anterior quadrant, clockwise rotation, and final vectors of slow inscription located in the right quadrants. Right sagittal plane: initial vectors slowly inscribed and directed downward and leftward, ORS loop almost completely located in the upper anterior quadrant, and counterclockwise rotation. T-loop directed downward and slightly backward: positive $\mathrm{T}$ wave in aVF and negative in V2. Conclusion: pacing rhythm with LAFB + atypical LAFB. 


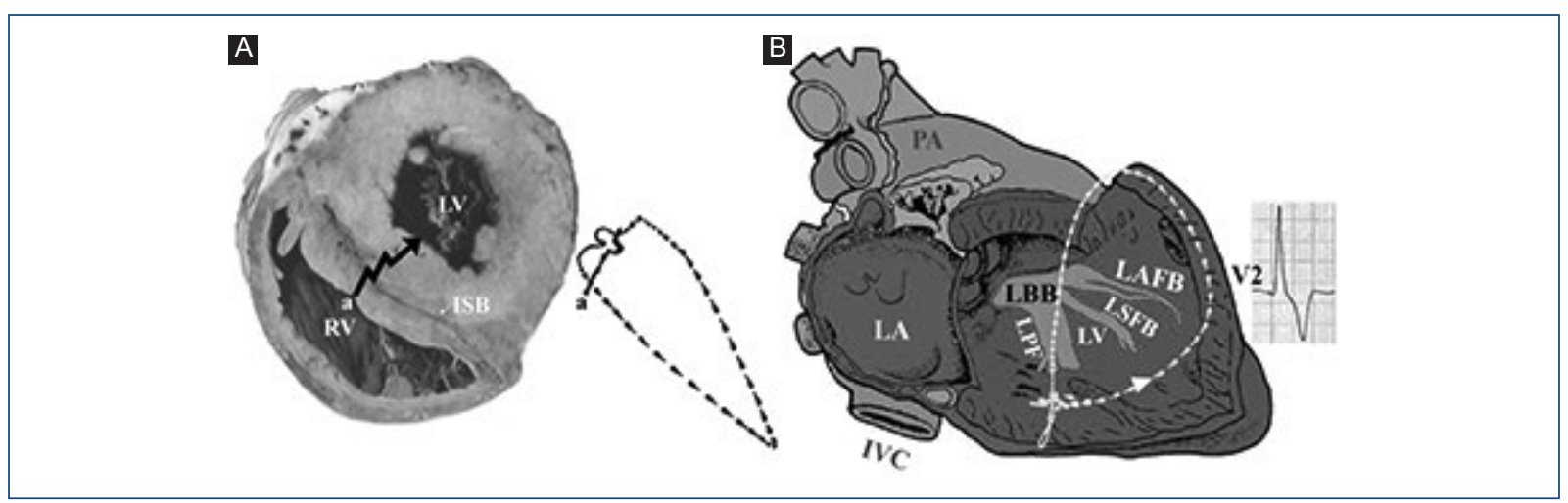

Figure 3. Ventricular activation route in the horizontal. A: and right sagittal. B: views. LPF: left posterior fascicle; LBB: left bundle branch; LSFB: left septal fascicular block; LAFB: left anterior fascicular block; LA: left atrium; LV: left ventricle; ISB: intraseptal barrier; a: subtricuspid region; PA: pulmonary artery; IVC: inferior vena cava; RV: right ventricle.

demonstrated the same using contrast-enhanced micro-computed tomography associated with high-resolution three-dimensional (3D) imaging of the human cardiac conduction system. This study was the first $3 \mathrm{D}$ representation of the cardiac conduction system within an ex vivo intact human heart in an attitudinally correct position.

There are several pieces of evidence that indicate an active role in the left ventricular (LV) activation pathway inside of the LV following three pathways ${ }^{10-12}$.

The second ECG of our patient shows a rather unique combination of the left-sided conduction block in the setting of a temporary pacemaker lead (Fig. 2): in the extremity leads, there is atypical left anterior fascicular block (LAFB) (by the absence of the first middle septal vector), and in the precordial leads, there are prominent anterior QRS forces, and the ECG criteria of LSFB are fulfilled.

Sung et al. hypothesized that retrograde conduction over the LSF produces alternate fascicular patterns as well as narrow forms of ventricular tachycardia (VT). Ablation of the respective fascicle was successful in abolishing fascicular tachycardia but did not preclude the development of bundle branch reentrant VT, unless the LSF was targeted and ablated. This manuscript strongly supports the trifascicular nature of the $\mathrm{LBB}^{13}$. Akhtar et al. ${ }^{10}$ found some evidence that more convincingly than before brought together the trifascicular nature of the LBB and active participation of the LSF in the LV activation.

Recently, Upadhyay et al. were able to delineate septal conduction in an LBBB case. These authors performed detailed intracardiac mapping of the left septal conduction system to assess for the presence and level of complete conduction block in the HPS. They studied patients with and without complete conduction block in the His conduction system. They observed heterogeneous septal conduction in patients with a surface LBBB pattern, ranging from no discrete block to complete conduction block. When block was present, they observed pathology localized within the left-sided His fibers, which was most amenable to corrective $H B$ pacing by recruitment of latent Purkinje fibers. ECG criteria for LBBB incompletely predicted complete conduction block, and intracardiac data might be useful in refining patient selection for resynchronization therapy ${ }^{14}$.

\section{Conclusion}

We have presented a patient case, where temporary pacemaker leads implantation in the subtricuspid region resulted in ECG findings compatible with the LAFB + LSFB. To the best of our knowledge, this is the first case ever published with these ECG features in this clinical setting. We think that this case adds to our understanding of the LSF in the human heart. Without detracting from the importance of the original Rosenbaum et al. contribution, some investigators have questioned various aspects of the basic hemiblock concept.

\section{Conflicts of interest}

None.

\section{Funding}

None. 


\section{Ethical disclosures}

Protection of human and animal subjects. The authors declare that no experiments were performed on humans or animals for this study.

Confidentiality of data. The authors declare that no patient data appear in this article.

Right to privacy and informed consent. The authors declare that no patient data appear in this article.

\section{References}

1. El-Sherif N, Scherlag BJ, Lazarra R, Samet P. Pathophysiology of tachycardia and bradycardia-dependent block in the canine proximal his-purkinje system after acute myocardial ischemia. Am J Cardiol. 1974;33:529-40.

2. Narula OS, Scherlag BJ, Samet P, Javier RP. Atrioventricular block Localization and classification by his bundle recordings. Am J Med. 1971;50:146-65

3. Tawara S. Das Reizleitungssystsem des Saeugetierherzens: eine Anatomhistologische Studie Ueber die Atrioventriculaer Buendel und die Purkinjeschen Faden. Germany: Jena, Gustav Fischer; 1906.
4. Pérez-Riera AR, Barbosa-Barros R, Daminello-Raimundo $R$, de Abreu LC, Nikus K. The tetrafascicular nature of the intraventricular conduction system. Clin Cardiol. 2019;42:169-74.

5. Demoulin JC, Kulbertus HE. Histopathological examination of concept of left hemiblock. Br Heart J. 1972;34:807-14.

6. Demoulin JC, Kulbertus HE. Left hemiblocks revisited from the histopathological viewpoint. Am Heart J. 1973;86:712-3.

7. Kulbertus HE, Demoulin JC. Pathological basis of concept of left hemiblock. In: Wellens HJ, Lie KI, Janse MJ, editors. The Conduction System of the Heart. Philadelphia, PA, USA: Lea and Febiger; 1978. p. 287-95.

8. Kulbertus HE. Concept of left hemiblocks revisited. A histopathological and experimental study. Adv Cardiol. 1975;14:126-35.

9. De Almeida MC, Lopes F, Fontes P, Barra F, Guimaraes R, Vilhena V, et al. Ungulates heart model: a study of the purkinje network using India ink injection, transparent specimens and computer tomography. Anat Sci Int. 2015;90:240-50.

10. Akhtar M. Human his-purkinje system: normal electrophysiologic behavior. Card Electrophysiol Clin. 2016;8:641-82.

11. Ibarrola M, Chiale PA, Pérez-Riera AR, Baranchuk A. Phase 4 left septal fascicular block. Heart Rhythm. 2014;11:1655-7.

12. Sun $H$, Hong $Y$, Jin $T$. A case report of different degrees of the left anterior, septal and posterior fascicular branch block. Ann Noninvasive Electrocardiol. 2015;20:189-92.

13. Sung RK, Kim AM, Tseng ZH, Han F, Inada K, Tedrow UB, et al. Diagnosis and ablation of multiform fascicular tachycardia. J Cardiovasc Electrophysiol. 2013;24:297-304.

14. Upadhyay GA, Cherian T, Shatz DY, Beaser AD, Aziz Z, Ozcan C, et al. Intracardiac delineation of septal conduction in left bundle-branch block patterns. Circulation. 2019;139:1876-88 